\title{
Motor responses of human gastrointestinal tract to 5-hydroxytryptamine in vivo and in vitro
}

\author{
J. J. MISIEWICZ, SHEILA L. WALLER, AND MARTIN EISNER ${ }^{1}$ \\ From the Medical Research Council Gastroenterology Research Unit, Central Middlesex Hospital, London
}

EDITORIAL SYNOPSIS This paper reports studies on the effects of serotonin on gastrointestinal motility in vivo and on muscle strips in vitro. Serotonin stimulates upper and lower small intestinal motility but inhibits activity in the stomach and colon. This effect is apparently a direct one on the smooth muscle. These studies fit in well with the observed effect in man in the carcinoid syndrome, as patients with increased urinary excretion of 5HIAA have been shown to have hypermotility of the small intestine and hypomotility of the colon.

The alimentary tract is the main source of 5-hydroxytryptamine (5HT, serotonin) in the body, but the physiological role of this amine is as yet uncertain. Bülbring and Crema (1958) have shown that 5HT potentiates the peristaltic reflex when applied to the mucosal surface of the guinea-pig ileum in vitro. In man, intravenous injections of serotonin stimulate pressure waves in the jejunum and ileum (Hendrix, Atkinson, Clifton, and Ingelfinger, 1957) but inhibit the distal colon (Fink and Friedman, 1960). It is possible therefore that serotonin causes the alimentary symptoms of the carcinoid syndrome. In vitro, 5HT contracts human muscle strips from the small intestine but inhibits strips from the colon (Fishlock and Parks, 1963).

The application of in vitro techniques to the study of human alimentary muscle is an important advance, but cannot replace studies in vivo. We have therefore investigated the effect of 5-hydroxytryptamine both in vivo and in vitro on the stomach, small intestine, and colon. In addition, experiments were performed on strips of oesophageal muscle in vitro. We have also recorded the motility of the small intestine and colon in a patient with the carcinoid syndrome.

\section{METHODS AND MATERIALS}

MEASUREMENT OF INTRALUMINAL PRESSURES IN PATIENTS Thirty-nine patients were studied. Twenty-two had the irritable bowel syndrome, abdominal pain, or constipation, three had proctitis, three steatorrhoea, and the remaining 11 suffered from a variety of gastrointestinal disorders. No specific trend emerged in any of the diagnostic groups in response to 5HT and the results from all the patients were analysed together. Most patients experienced mild side-effects during the injection of 5HT, consisting of a feeling of warmth of the face or local pain in the vein.

Intraluminal pressures in the stomach, intestine, and proximal and distal colon were telemetered with an ingestible radio capsule (Rowlands and Wolff, 1960; Connell, McCall, Misiewicz, and Rowlands, 1963). The radio capsule was localized by screening with an image amplifier and from the characteristics of the pressure record. Configuration of pressure waves allowed differentiation between gastric, upper and lower small intestinal and colonic tracings. In addition to pressure, the radio capsule telemetered data about its own movement in relation to an aerial outside the body, which were valuable in studies of gastric motility. Pressures in the sigmoid and the rectum were recorded with $4 \times 7 \mathrm{~mm}$. air-filled balloons (Atkinson, Edwards, Honour, and Rowlands, 1957), connected to Sanborn 276B transducers with polyethylene tubes. The balloons were placed at sigmoidoscopy 10 and $20 \mathrm{~cm}$. from the anal margin. Following sigmoidoscopy 30 minutes were allowed to elapse before any records were taken. Telemetering and intubation manometry were combined for simultaneous records of intraluminal pressures from the proximal colon and the sigmoid and rectum (Misiewicz, Connell, and Pontes). A stethograph was used throughout the studies.

DESIGN OF STUDY AND ANALYSIS OF PRESSURE RECORDS With the patients resting comfortably on a couch or on a mattress placed upon the $x$-ray table, a needle was placed in an arm vein and kept patent with heparinized saline. Intraluminal pressures were then recorded continuously during four consecutive $8 \mathrm{~min}$. periods as follows:

\begin{tabular}{lll} 
Period & & Injection \\
\hline I & Control & No injection \\
II & Placebo & N saline, $2 \mathrm{ml} . / \mathrm{min}$. intravenously \\
III & SHT & 5HT (Sandoz) $0.5 \mathrm{mg} . / \mathrm{min}$. intraven- \\
& ously. Total dose $4.0 \mathrm{mg}$. \\
IV & Post injection & No injection
\end{tabular}


The patients were either fasting or had had a meal 30 minutes or more before the study. Fifteen of the colonic records were taken 20 to 30 minutes following $0.75 \mathrm{mg}$. of Prostigmin intramuscularly.

Pressure activity in each eight-minute period was expressed in terms of a motility index (M.I.). In gastric and colonic records the sum of the products of duration and amplitude of each wave was divided by time.

$$
\text { M.I. }=\frac{\sum(\text { Duration } \times \text { Amplitude })}{\text { Time (minutes) }}
$$

The shape of small intestinal waves made measurement of the duration of each pressure spike difficult. The M.I. was therefore calculated by multiplying the sum of the amplitudes by the number of waves and dividing by time.

$$
\text { M.I. }=\frac{\left(\sum \text { Amplitudes }\right) \times \text { No. of Waves }}{\text { Time (minutes) }}
$$

Each patient acted as his own control. The significance of differences between the consecutive eight-minute observation periods was calculated by means of Student's $\mathrm{t}$ test.

The number of studies from each part of the gut is shown in Table I. Only one study was made in each part of the alimentary tract in any one patient. In 11 studies of gastric motility, nine records were telemetered from the body and two from the fundus of the stomach. In 11 small intestinal studies pressures were telemetered from the duodenum or jejunum; in 14 studies the radio pill was in the right iliac fossa and the pressure record was ileal in character. There was no overlap in the position of the capsule as found by fluoroscopy between the two groups. There were 17 studies from the proximal colon (caecum to right transverse), 10 from the distal colon (left transverse and descending), and 21 from both the sigmoid and the rectum. In 21 colonic records pressures were obtained simultaneously from the proximal or distal colon and the sigmoid and rectum.
TABLE I

DIFFERENCES IN THE M.I. BETWEEN THE FOUR OBSERVATION

\begin{tabular}{|c|c|c|c|c|}
\hline Site & $\begin{array}{l}\text { No. of } \\
\text { Studies }\end{array}$ & $\begin{array}{l}\text { Control } \\
\text { v. } \\
\text { Placebo }\end{array}$ & $\begin{array}{l}\text { Placebo } \\
\nu . \\
5 H T\end{array}$ & $\begin{array}{l}\text { Post-injection } \\
v_{\text {. }} \\
\text { Placebo }\end{array}$ \\
\hline Stomach & 11 & $P>0.1$ & $\begin{array}{l}\text { Inhibition } \\
P<0.01\end{array}$ & $P>0.1$ \\
\hline $\begin{array}{l}\text { Upper small } \\
\text { intestine }\end{array}$ & 11 & $P>0.1$ & $\begin{array}{l}\text { Stimulation } \\
P<0.05\end{array}$ & $P>0.1$ \\
\hline $\begin{array}{l}\text { Lower small } \\
\text { intestine }\end{array}$ & 14 & $P>0.1$ & $P>0.1$ & $\begin{array}{l}\text { Stimulation } \\
P<0.02\end{array}$ \\
\hline Proximal colon & 17 & $P>0 \cdot 1$ & $\begin{array}{l}\text { Inhibition } \\
P<0.01\end{array}$ & $P>0.1$ \\
\hline Distal colon & 10 & $P>0.1$ & $\begin{array}{l}\text { Inhibition } \\
P<0.01\end{array}$ & $P>0.1$ \\
\hline Sigmoid & 21 & $P>0 \cdot 1$ & $\begin{array}{l}\text { Inhibition } \\
\mathrm{P}<0.001\end{array}$ & $\begin{array}{l}\text { Inhibition } \\
P<0.05\end{array}$ \\
\hline Rectum & 21 & $P=0.05$ & $\begin{array}{l}\text { Inhibition } \\
P<0.002\end{array}$ & $P>0.1$ \\
\hline
\end{tabular}
PERIODS

EXPERIMENTS IN VITRO Surgical specimens, none of which showed evidence of obstruction, were placed in a modified Krebs solution immediately after resection. Mucosa-free strips of circular and longitudinal intestinal muscle measuring about $20 \times 3 \mathrm{~mm}$. were dissected off and mounted in an organ bath (Bennett, 1964) maintained at $37^{\circ} \mathrm{C}$. and filled with Krebs solution gassed with $95 \% \mathrm{O}_{2}$ and $5 \% \mathrm{CO}_{2}$. The strips were equilibrated for one hour before any drugs were added. Muscle contractions against a load of 1 to $3 \mathrm{~g}$. were recorded with an isotonic lever connected to a transducer and an Inkwell pen writer. Malignant infiltration of the strips was excluded by subsequent histological examination. Standard pharmacological procedure was followed: a timed cycle of agonists was established and repeated in the same sequence in the presence of appropriate an-

\section{Movement}

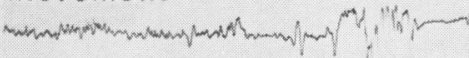
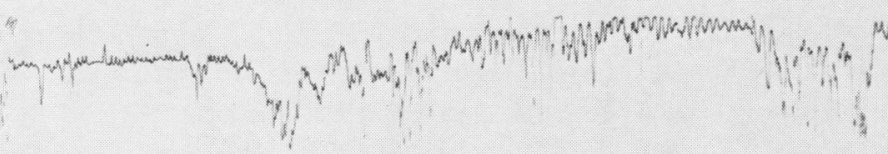

1 Min

Stethogroph

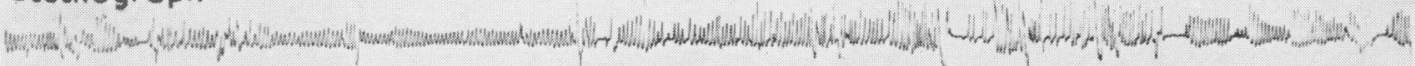

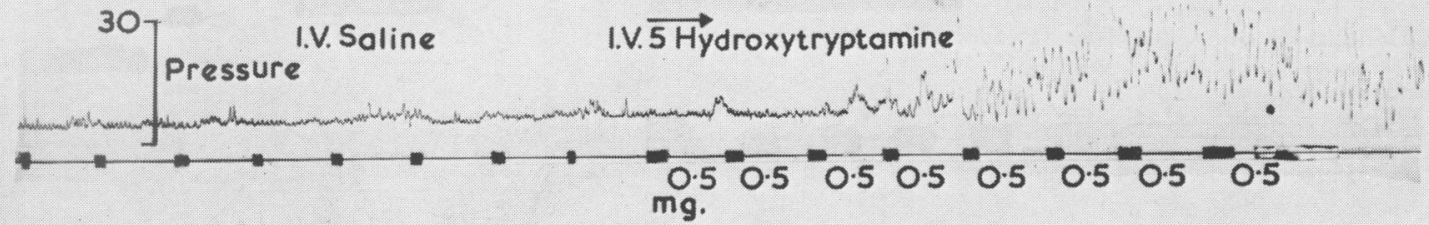

FIG. 1. Stimulation of pressure activity in the upper small intestine by 5HT. Pressure in cm. $\mathrm{H}_{2} \mathrm{O}$. 
tagonists, after 10 minutes' incubation with the latter. Contact times and washing periods were kept constant for each strip. Tachyphylaxis to 5HT was marked in many strips and was allowed for in the time cycle. Blocking agents mentioned in the results antagonized the actions of the appropriate agonists. Drug concentrations are expressed in micrograms of the salt per millilitre of fluid in the bath.

The following drugs were used: acetylcholine $\mathrm{HCl}$, nicotine hydrogen tartrate, dimethylphenylpiperazinium iodide (D.M.P.P.), adrenaline $\mathrm{HCl}$, 1-nor-adrenaline, isoprenaline sulphate, 5-hydroxytryptamine creatinine sulphate, histamine acid phosphate, physostigmine sulphate, prostigmine methyl sulphate, atropine sulphate, hexamethonium bromide, procaine hydrochloride, pronethalol $\mathrm{HCl}$, phentolamine, and mepyramine maleate.

\section{RESULTS}

EFFECT OF 5HT ON SMALL INTESTINAL MOTILITY 5-hydroxytryptamine stimulated the small intestine both in vivo and in vitro.

In vivo, following the injection of serotonin there was increased pressure activity which was often accompanied by a rise in baseline, especially in the jejunum (Fig. 1). Analyses of the pressure records from the upper small intestine are shown in Figure $2 \mathrm{a}$. While the control and placebo periods did not differ significantly, during the injection of 5HT there was a significant rise in the M.I., the activity returning to control levels in the post-injection period (Table I). In the ileum the main stimulating effect occurred in the post-injection period (Fig. 2b, Table I). In vitro, 5HT (0.01-10.0 $\mu \mathrm{g}$.) caused a con-

TABLE II

NUMBER OF MUSCLE STRIPS FROM VARIOUS PARTS OF THE ALIMENTARY TRACT

\begin{tabular}{llc} 
Site & Type of Muscle & No. of strips \\
\hline Stomach body & Circular & 12 \\
Stomach antrum & Longitudinal & 8 \\
& Circular & 4 \\
Small intestine & Longitudinal & 5 \\
& Circular & 16 \\
Caecum & Longitudinal & 5 \\
Left colon & Circular & 5 \\
Oesophagus & Circular & 12 \\
Oesophagus achalasia & Longitudinal & 6 \\
& Circular & 11 \\
& Longitudinal & 5 \\
& Sphincteric segment & \\
& Longitudinal & 3
\end{tabular}

traction of circular and longitudinal muscle strips from the upper and lower small intestine (Table II). This response was not antagonized by atropine (1.0$10.0 \mu \mathrm{g}$.) or hexamethonium $(10 \cdot 0-20.0 \mu \mathrm{g}$.), as shown in Fig. 3, nor by procaine $(5 \cdot 0-50 \cdot 0 \mu \mathrm{g}$.),
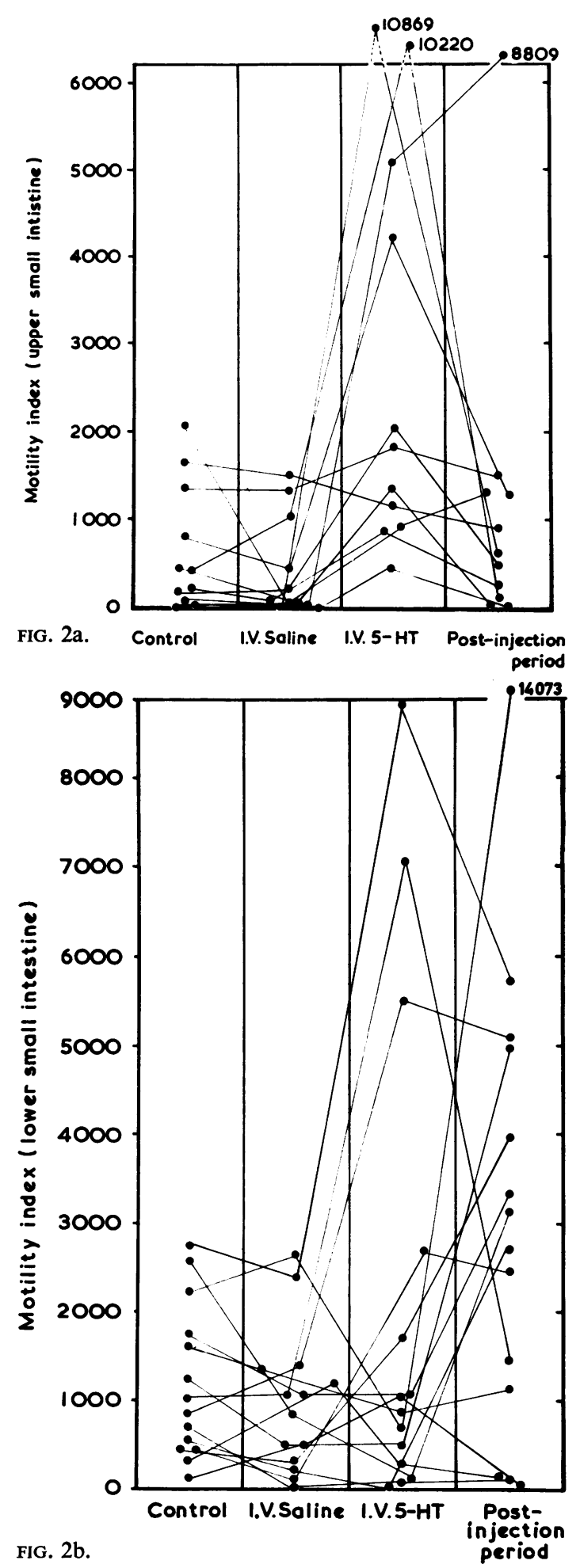

FIGS. $2 \mathrm{a}$ and $2 \mathrm{~b}$. Effect of $5 H T$ on the motility of upper and lower small intestine. 


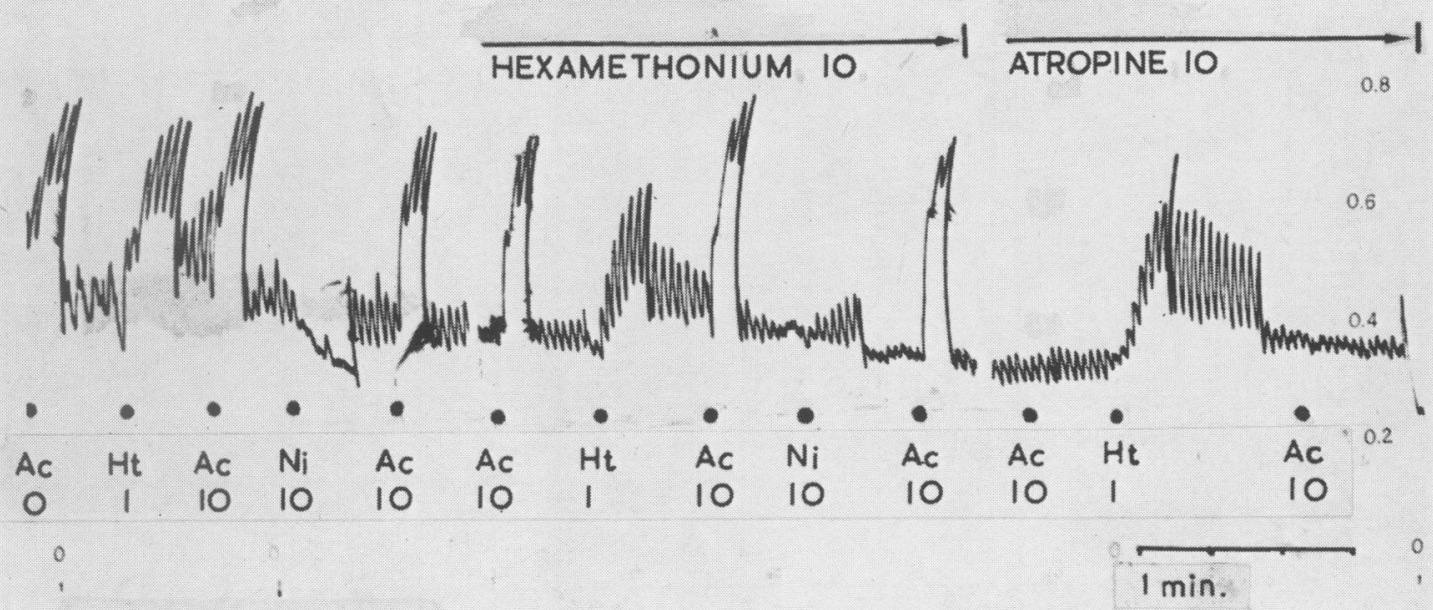

FIG. 3. In vitro response of ileal circular muscle to $5 H T$, not abolished by hexamethonium or atropine. Ac = acetylcholine, $\mathrm{Ht}=5 \mathrm{HT}, \mathrm{Ni}=$ nicotine. Contact times: $30 \mathrm{sec}$. for acetylcholine, $60 \mathrm{sec}$. for $5 \mathrm{HT}$ and nicotine. Three-minute intervals between drugs with recorder stopped for two minutes.

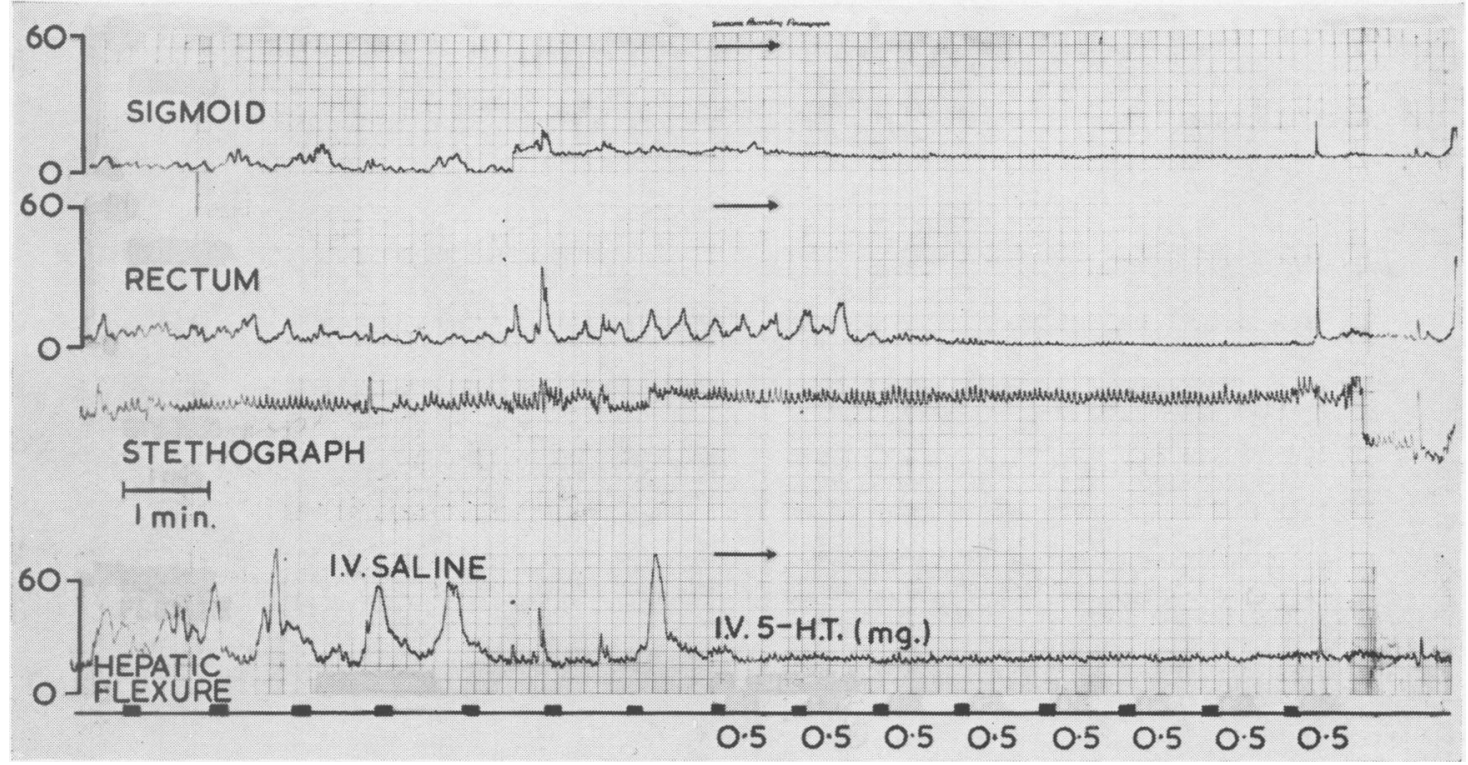

FIG. 4. Inhibition of pressure activity of the proximal colon, sigmoid and rectum by $5 \mathrm{HT}$. Pressure in cm. $\mathrm{H}_{2} \mathrm{O}$.

pronethalol $(10 \cdot 0-20 \cdot 0 \mu \mathrm{g}$.$) , or mepyramine (5 \cdot 0-$ $20.0 \mu \mathrm{g}$.$) .$

EFFECT OF 5HT ON COLONIC MOTILITY In contrast to the small intestine, colonic muscle was inhibited by 5HT both in vivo and in vitro.

In vivo, $4 \mathrm{mg}$. of serotonin rapidly inhibited the pressure activity of the colon (Fig. 4). Analysis of the pressure tracings (Fig. 5a, b, c, and d) shows a highly significant fall in the M.I. during the injection of $5 \mathrm{HT}$ in all parts of the colon that were studied (Table I). Inhibition, which was usually complete, was rapid in onset and ended abruptly. Significant inhibition did not persist beyond the injection period except in the sigmoid. The placebo did not alter the M.I. although in the rectum the conventional level 

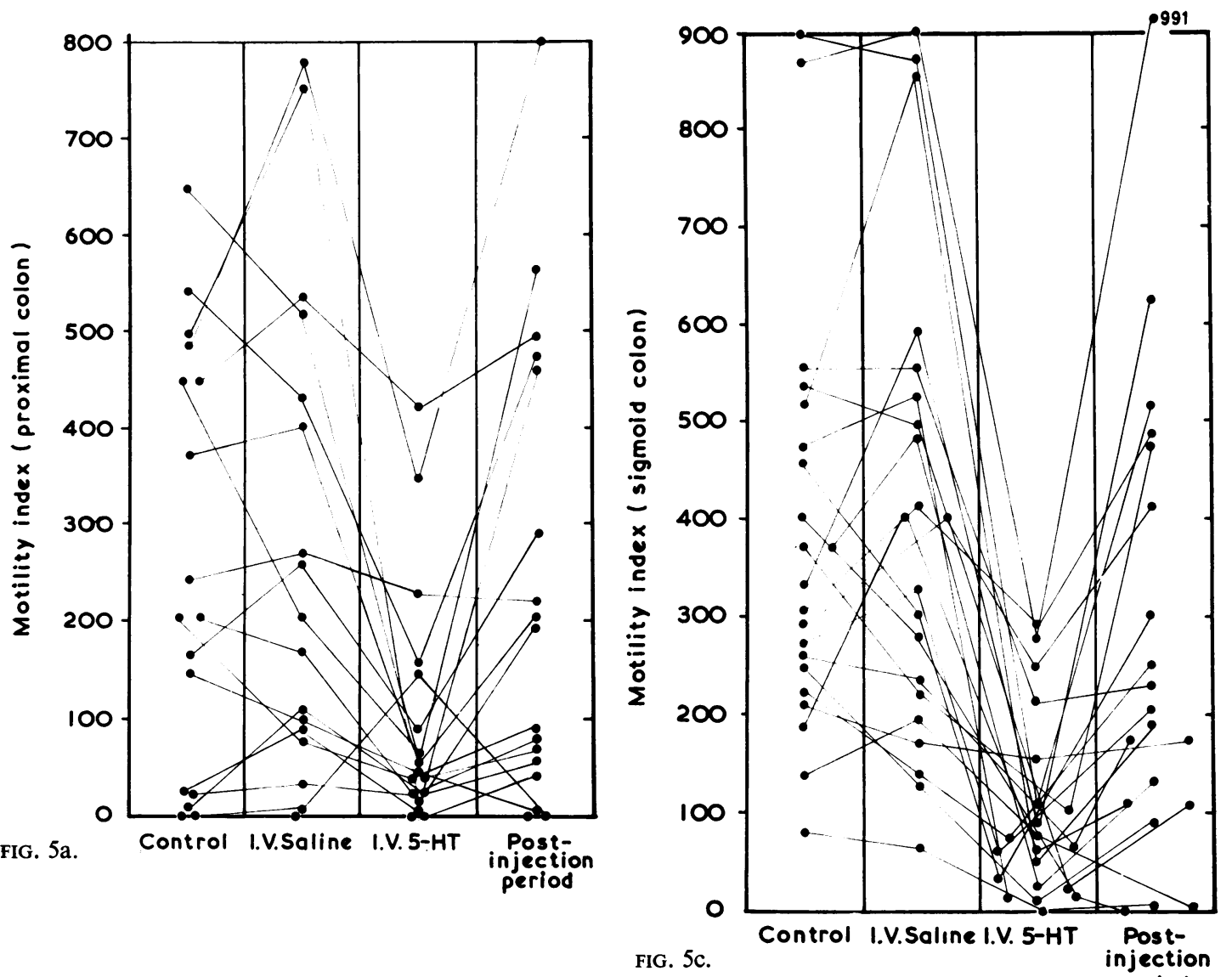

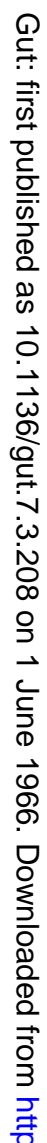
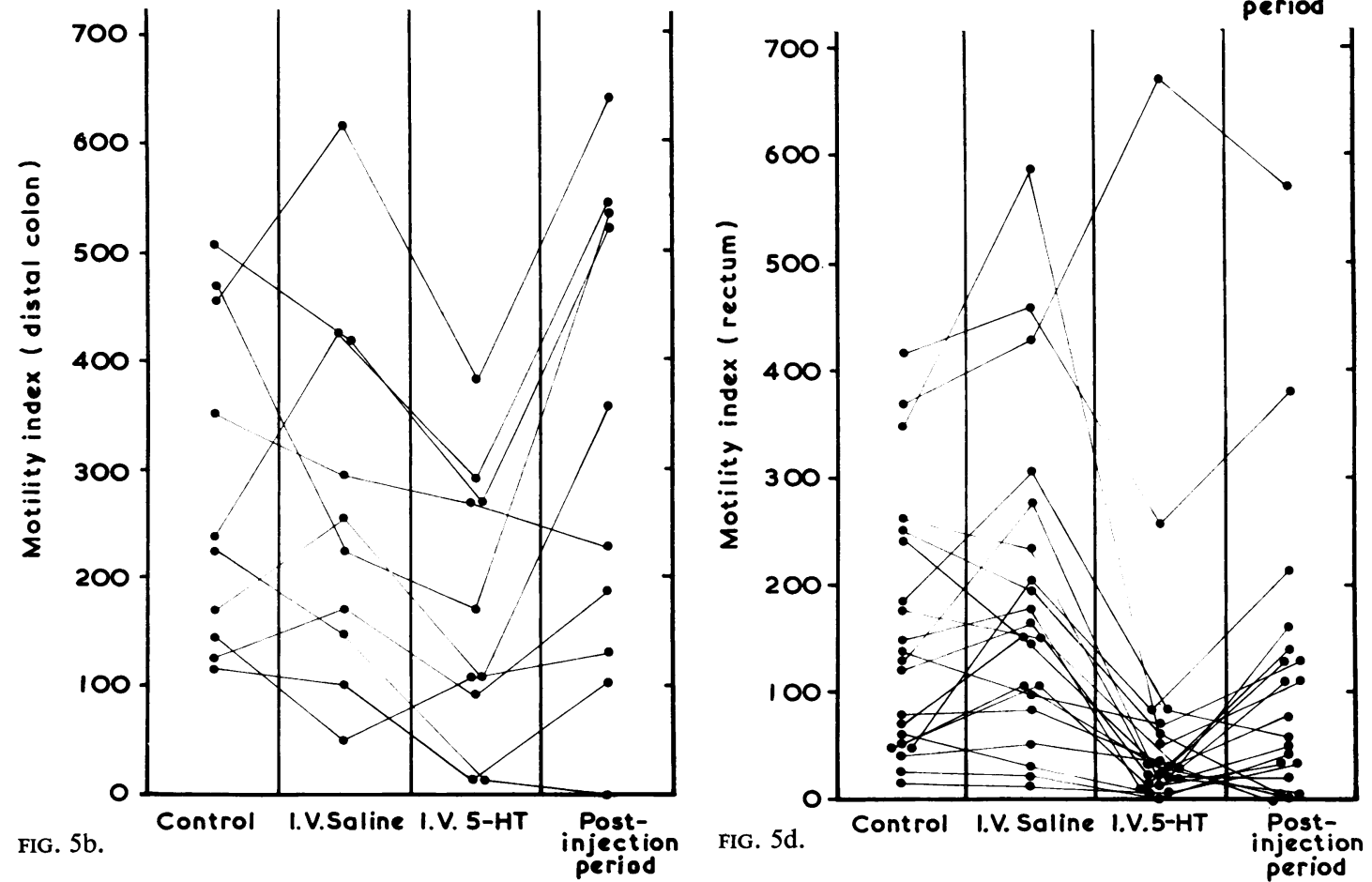

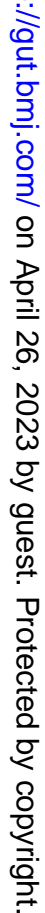

FIGS. 5a and 5b. Effect of $5 H T$ on the motility of the proximal and distal colon.

FIGS. 5c. and 5d. Effect of $5 H T$ on the motility of the sigmoid and rectum. 
1 min.

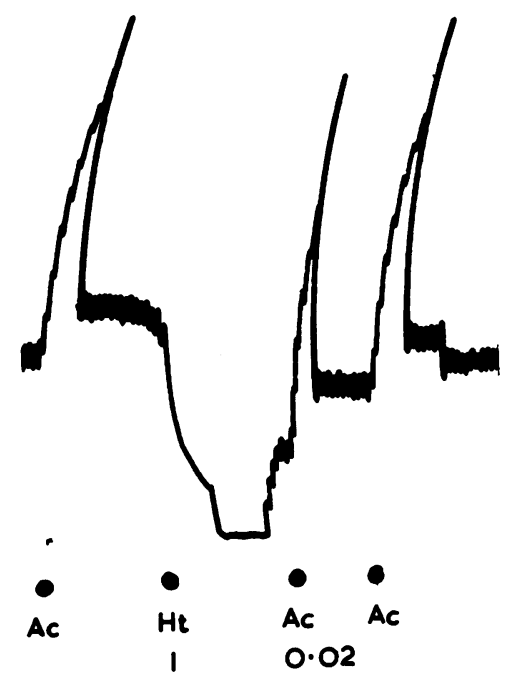

FIG. 6. In vitro response to $5 H T$ of taenia from the descending colon. $A c=$ acetylcholine, $H t=5 H T$. Contact times: $30 \mathrm{sec}$. for acetylcholine, $60 \mathrm{sec}$. for $5 \mathrm{HT}$. Three-minute intervals between drugs with recorder stopped for two minutes.

of significance was just reached. However, this change was the opposite to that produced by serotonin, and rectal motility was significantly lower in the 5HT period than in either the control or the placebo period (Table I). In vitro, 5HT (0.04-5.0 $\mu \mathrm{g}$.) inhibited circular muscle strips from the transverse and descending colon (Table II). All the strips of longitudinal muscle were inhibited by serotonin (0.1-1.0 $\mu$ g.) (Fig. 6), but in three studies contraction followed after the drug had been washed out. The inhibition was not antagonized by pronethalol (5.0-10.0 $\mu \mathrm{g}$.$) , hexamethonium (10.0-20.0 \mu \mathrm{g}$.), mepyramine $(5.0 \mu \mathrm{g}$.$) , or atropine (10.0 \mu \mathrm{g}$.$) .$ Experiments on caecal circular muscle (Table II) did not yield consistent results, one strip being inhibited $(0.5 \mu \mathrm{g}$.), one stimulated $(0.01-1 \cdot 0 \mu \mathrm{g}$.), and three showing no response to 5HT (0.01$100 \cdot 0 \mu \mathrm{g}$.).

EFFECT OF 5HT ON GASTRIC MOTILITY 5-Hydroxytryptamine inhibited gastric motility in patients, but gave a variable response in vitro.

In vivo, serotonin inhibited both intragastric pressures and movement (Fig. 7). Analysis of the traces

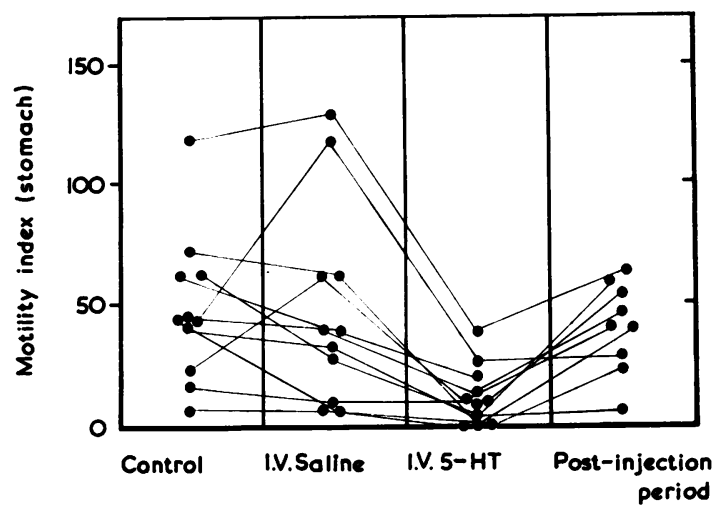

FIG. 8. Effect of 5HT on the motility of the stomach.

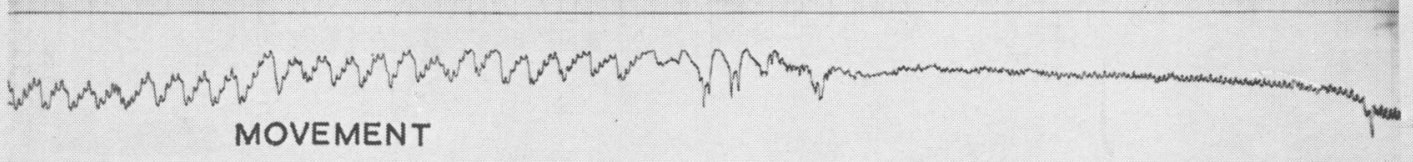

$\stackrel{\mathrm{min}}{\mathrm{I}}$

STETHOGRAPH

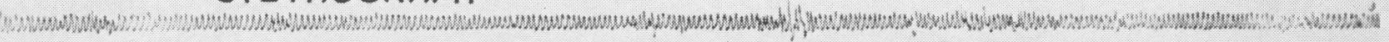

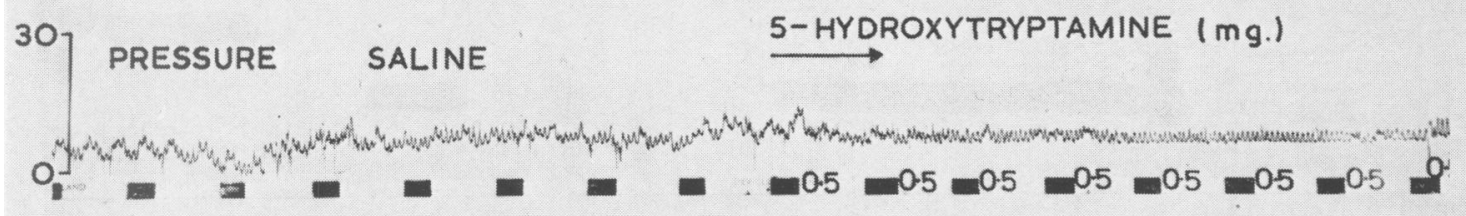

FIG. 7. Inhibition of gastric pressure activity and movement by $5 \mathrm{HT}$. Pressure in $\mathrm{cm} . \mathrm{H}_{2} \mathrm{O}$. 


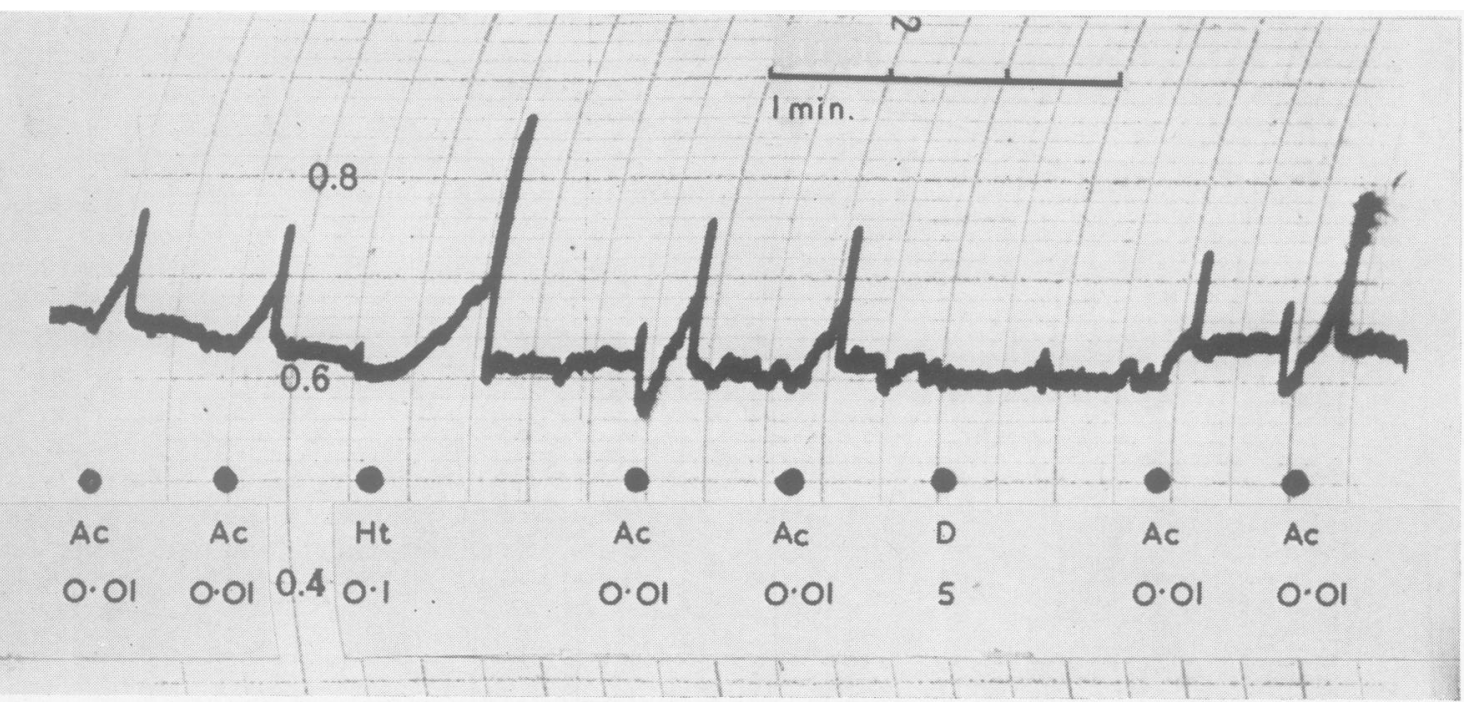

FIG. 9. Response to $5 H T$ of longitudinal oesophageal muscle from achalasia of the cardia in vitro. Ac $=$ acetylcholine, $H t=5 H T, D=D M P P$. Contact times: $30 \mathrm{sec}$. for acetylcholine, $60 \mathrm{sec}$. for 5 HT and DMPP. Three-minute intervals between drugs with recorder stopped for two minutes.

(Fig. 8) showed a significant fall in the motility index during the period when 5HT was injected while saline had no significant effect (Table I). In vitro, in 23 experiments (Table II), serotonin contracted eight strips, inhibited two, and had no effect on 13. The unresponsive strips were normally sensitive to acetylcholine (0.05-10.0 $\mu \mathrm{g}$.).

STUDIES IN VITRO ON OESOPHAGEAL MUSCLE All the longitudinal and circular oesophageal muscle strips studied contracted to 5HT (0.5-10.0 $\mu \mathrm{g}$.) (Table II). This response persisted in the presence of atropine $(10 \cdot 0-100 \cdot 0 \mu \mathrm{g}$.), phentolamine $(5 \cdot 0-100 \cdot 0 \mu \mathrm{g}$.$) ,$ pronethalol (10.0-20.0 $\mu \mathrm{g}$.$) , mepyramine (10.0 \mu \mathrm{g}$.$) ,$ and hexamethonium $(10 \cdot 0-20 \cdot 0 \mu \mathrm{g}$.).

In three strips of longitudinal oesophageal muscle taken from patients with achalasia of the cardia, although the myenteric ganglia were shown to be absent both pharmacologically and histologically, 5HT (0.01-1.0 $\mu$ g.) caused a contraction (Fig. 9).

INTESTINAL MOTILITY IN A PATIENT WITH CARCINOID SYNDROME AND DIARRHOEA A 56-year-old woman developed typical facial flushing and severe watery diarrhoea 12 months after a carcinoid tumour of the caecum had been resected. Urinary 5HIAA excre-

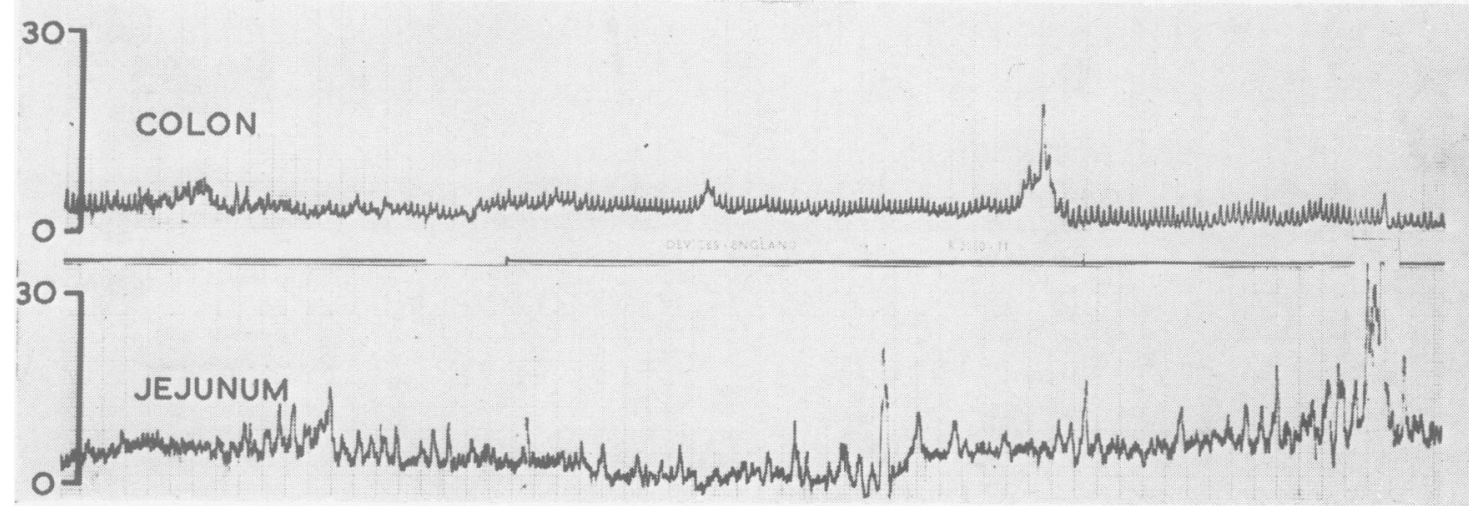

FIG. 10. Pressure activity in the jejunum and transverse colon of a patient with the carcinoid syndrome. 
tion was elevated. Studies of intestinal motility in the fasting state showed a hyperactive small intestine, but the colonic record was inactive (Fig. 10).

\section{DISCUSSION}

In vivo, the same dose of serotonin given over the same period of time stimulated the small intestine but inhibited the stomach and the right and left colon. In vitro, preliminary pharmacological analysis suggested that the site of action of 5HT may be directly on the smooth muscle.

The significant rise in the M.I. of the small gut after parenteral serotonin confirms observations made by Hendrix et al. (1957) and by Daniel, Honour, and Bogoch (1960). In the present study both upper and lower small intestine were stimulated. The effect on the upper small gut occurred during the injection of 5HT. The ileum was stimulated mainly in the post-injection period, although in four of the 14 studies a marked rise in pressure activity coincided with the administration of serotonin. The slower onset of ileal activity may have been induced reflexly by filling with upper small gut contents, but distal propulsion of the radio capsule was not prominent in upper intestinal studies. Moreover ileal muscle has been shown to be sensitive to serotonin in vitro (present results; Bennett, 1965). Post-prandial or prostigmine-induced activity of the right and left colon was significantly inhibited by 5HT. Inhibition of the distal colon by serotonin is generally accepted (Schmid and Kinzlmeier, 1959; Fink and Friedman, 1960; Ramorino, Casale, Amoruso, Arullani and Ammaturo, 1965), but either stimulation or inhibition of the right colon has been reported by various workers.

Débray and Besançon (1961) failed to stimulate the right colon with $0.5 \mathrm{mg}$. of $5 \mathrm{HT}$ while inducing activity of the small intestine. After $1.5 \mathrm{mg}$. of 5HT Fink and Friedman (1960) observed that the right colon was stimulated while the left was inhibited. Ramorino and her colleagues (1965) regularly stimulated the right colon, while inhibiting the left, with $4 \mathrm{mg}$. of serotonin given over two minutes, and contractions of the ascending colon following 5HT have been seen fluoroscopically (Torsoli, 1965). In the present series stimulation was observed in only one in 17 studies of the proximal colon, although control activity was low in five subjects (Fig. 5a). These discrepancies may be due to differing rates of drug administration, but in a further five studies with $4 \mathrm{mg}$. of 5HT given in two minutes there was a rise of the M.I. in only one (Misiewicz and Waller, unpublished observations). Different selection of subjects or variation in the response of the colon to $5 \mathrm{HT}$ in the basal or stimulated state may also play a part. We have found that the response in vitro of caecal muscle to 5HT was variable, in contrast to the left colon, which was regularly inhibited.

The fact that gastric motility was inhibited is interesting in view of a similar effect of 5HT on human and canine gastric secretion of $\mathrm{HCl}$; in man, this inhibition of acid secretion was accompanied by cessation of motor activity (Schmid and Kinzlmeier, 1959; Black, Fisher, and Smith, 1958).

The degree of correlation found between the studies in vivo and in vitro was encouraging. The differential effect of serotonin on small intestinal and left colonic motility in patients was also demonstrated on the isolated muscle strip. Response of caecal circular muscle strips was variable. In patients gastric motility was inhibited, but the majority of gastric strips from all parts of the stomach were unresponsive to 5HT. The absence in vitro of nervous and hormonal pathways which may maintain the peristaltic activity of the intact human stomach probably accounts for this difference. Fishlock, Parks, and Dewell (1965) also found that gastric muscle was generally unresponsive to 5HT in vitro, except that longitudinal muscle from the body was stimulated. Preliminary pharmacological analysis suggests that the site of action of serotonin may be directly on the smooth muscle cell. Inhibitory or excitatory actions of 5HT were not antagonized by ganglionic blockade, nor by the blockade of cholinergic, adrenergic, or histaminergic pathways. Our results agree with other studies on human alimentary muscle in vitro (Fishlock and Parks, 1963; Bennett, 1965; Whitney, 1965). Wright and Shepherd (1966) found inhibition of circular but stimulation of longitudinal strips taken from the sigmoid colon of African patients suffering from sigmoid volvulus, while a variable response of longitudinal muscle to 5HT was reported by Bucknell and Whitney (1964). In this study serotonin inhibited both muscle layers from the distal colon in vitro, except that some longitudinal strips contracted after the drug had been washed out. It seems possible that details of technique may modify responses of the muscle strips in vitro and that data obtained in vivo should be borne in mind in the interpretation of results. The contraction of longitudinal and circular oesophageal muscle to 5HT in vitro does not appear to have been observed previously. Serotonin at this site also appeared to act directly on the muscle. Further evidence for direct action is the observation that 5HT stimulated aganglionic oesophageal muscle from patients with achalasia of the cardia.

These observations differ from those usually found in animals (Vane, 1957; Brownlee and Johnson, 1963), where it has been shown that serotonin acts on postganglionic fibres ( $\mathrm{M}$ receptors) or 
on smooth muscle cells (D receptors) (Gaddum and Picarelli, 1957), and that the $\mathrm{D} / \mathrm{M}$ ratio may vary from species to species and also in different parts of the alimentary tract in the same species (Day and Vane, 1963). It may be that the D receptors predominate in man.

If serotonin secreted in the body has actions resembling the pharmacological effects demonstrated above, then patients with the carcinoid syndrome who have diarrhoea and elevated urinary levels of 5HIAA should have hyperactivity of the small intestine and hypoactivity of the colon. This was so in the patient reported here, and Smith, Preshaw, and Sircus (1965) have made similar observations on two patients with carcinoid. Administration of a specific serotonin antagonist, methysergide, has been shown to relieve the diarrhoea, but had no effect on flushing attacks (Peart and Robertson, 1961). It is possible that although 5HT is no longer thought to cause the flush (Robertson, Peart and Andrews, 1962), it may be a factor in the production of abdominal symptoms in the carcinoid syndrome.

\section{SUMMARY}

The effect of serotonin on gastrointestinal motility in vivo has been compared with the response of human gastrointestinal muscle strips in vitro.

In patients, serotonin stimulated upper and lower small intestinal motility but inhibited the colon and the stomach. There was an encouraging degree of correlation between the studies in vivo and in vitro.

Pharmacological analysis in vitro suggested the site of action of 5HT to be directly on the smooth muscle.

These findings may be important in the mechanism of diarrhoea in the carcinoid syndrome.

We wish to thank Dr. F. Avery Jones and Dr. T. D. Kellock for permission to study patients under their care, Dr. E. N. Rowlands for advice and encouragement, Mr. J. W. P. Gummer and Mr. F. A. Henley for their kind cooperation, and Dr. R. A. B. Drury for the histological sections. Mr. A. Cronquist and Mr. T. Smith, M.Sc., gave invaluable technical help and Miss J. Lister assisted with the studies. The in vitro transducer, isotonic lever and amplifier were built to the design of Mr. D. W. Lywood, Department of Engineering, National Institute for Medical Research, Mill Hill, London.

\section{REFERENCES}

Atkinson, M., Edwards, D. A. W., Honour, A. J., and Rowlands, E. N. (1957). Comparison of cardiac and pyloric sphincters: a manometric study. Lancet, 2, 918-922.
Bennett, A. (1964). An improved isolated organ bath. J. Sci. Technol., 10, 176-177.

Bennett, A. (1965). A pharmacological investigation of human isolated ileum. Nature (Lond.), 208, 1289-1291.

Black, J. W., Fisher, E. W., and Smith, A. N. (1958). The effects of 5-hydroxytryptamine on gastric secretion in anaesthetized dogs. J. Physiol (Lond.), 141, 27-34.

Brownlee, G., and Johnson, E. S. (1963). The site of the 5-hydroxytryptamine receptor on the intramural nervous plexus of the guinea-pig isolated ileum. Brit. J. Pharmacol., 21, 306-322.

Bucknell, A., and Whitney, B. (1964). A preliminary investigation of the pharmacology of the human isolated taenia coli preparation. Ibid., 23, 164-175.

Bülbring, E., and Crema, A. (1958). Observations concerning the action of 5-hydroxytryptamine on the peristaltic reflex. Ibid., 13, 444-457.

Connell, A. M., McCall, J., Misiewicz, J. J. and Rowlands, E. N. (1963). Observations on the clinical use of radio pills. Brit. med. J., 2, 771-774.

Daniel, E. E., Honour, A. J., and Bogoch, A. (1960). Antagonism of serotonin-induced contraction and electrical activity in the ileum. Gastroenterology, 39, 62-73.

Day, M., and Vane, J. R. (1963). An analysis of the direct and indirect actions of drugs on the isolated guinea-pig ileum. Brit. $J$. Pharmacol., 20, 150-170.

Débray, C. H., and Besançon, F. (1961). Sérotonine (5-hydroxytryptamine) et motricité physiologique de l'intestin grêle humain. Recherches électromanométriques. Arch. Mal. Appar. dig., 50, 729-735.

Fishlock, D. J., and Parks, A. G. (1963). A study of human colonic muscle in vitro. Brit. med. J., 2, 666-667.

$\longrightarrow$ - - and Dewell, J. Veronica (1965). Action of 5-hydroxytryptamine on the human stomach, duodenum, and jejunum in vitro., Gut., 6, 338-342.

Fink, S., and Friedman, G. (1960). The differential effect of drugs on the proximal and distal colon. Amer. J. Med., 28, 534-540.

Gaddum, J. H., and Picarelli, Z. P. (1957). Two kinds of tryptamine receptor. Brit. J. Pharmacol., 12, 323-328.

Hendrix, T. R., Atkinson, M., Clifton, J. A., and Ingelfinger, F. J. (1957). The effect of 5-hydroxytryptamine on intestinal motor function in man. Amer. J. Med., 23, 886-893.

Misiewicz, J. J., Connell, A. M., and Pontes, F. (1966). Comparison of the effect of meals and prostigmine on the motility of the proximal and distal colon in patients with and without diarrhoea. Gut. To be published.

Peart, W. S., and Robertson, J. I. S. (1961). The effect of a serotonin antagonist (UML 491) in carcinoid disease. Lancet, 2, 1172 1174.

Ramorino, M. L., Casale, C., Amoruso, M., Arullani, P. and Ammaturo, M. V. (1965). In Acta Tertii Conventus Medicinae Internae Hungarici. Gastroenterologia, pp. 733-737.

Robertson, J. I. S., Peart, W. S., and Andrews, T.M. (1962). The mechanism of facial flushes in the carcinoid syndromes. Quart. J. Med., 31, 103-123.

Rowlands, E. N., and Wolff, H. S. (1960). The radio pill, telemetering from the digestive tract. Brit. Commun. Electron., 7, 598-601.

Schmid, E., and Kinzlmeier, H. (1959). Das Verhalten der Magenacidität und der Motilität im Verdauungstrakt des Menschen bei Infusion von Serotonin. Naunyn-Schmiedeberg's Arch. exp. Path. Pharmak., 236, 51-54.

Smith, A. N., Preshaw, R. M., and Sircus, W. (1965). Clinical features. in patients with the carcinoid syndrome. Gastroenterology, 48, 738-744.

Torsoli, A. (1965). Personal communication.

Vane, J. R. (1957). A sensitive method for the assay of 5-hydroxytryptamine. Brit. J. Pharmacol., 12, 344-349.

Whitney, B. (1965). A preliminary investigation of the pharmacology of longitudinal muscle strips from human isolated jejunum. J. Pharm. Pharmacol., 17, 465-473.

Wright, P. G., and Shepherd, J. J. (1966). Some observations on the response of normal human sigmoid colon drugs in vitro., Gut. 7, 41-51. 